\title{
Effects of an Exercise Intervention on Body Composition in Older Adult Males Diagnosed with Parkinson's disease: A Brief Report
}

\author{
Corey A Peacock ${ }^{1^{*}}$, Gabriel J Sanders ${ }^{2}$, Kayla A Wilson ${ }^{3}$, Emily J Fickes-Ryan ${ }^{4}$, Duane B Corbett ${ }^{3}$ and Angela L Ridgel ${ }^{3}$
}

${ }^{1}$ Nova Southeastern University, Fort Lauderdale, FL 33314, USA

${ }^{2}$ Northern Kentucky University, Highland Heights, KY 41099, USA

${ }^{3}$ Kent State University, Kent, $\mathrm{OH} 44240$, USA

${ }^{4}$ West Virginia University, Morgantown, WV 26506, USA

\begin{abstract}
The investigation examined the value of a multifaceted exercise intervention on body composition and strength, in those diagnosed with Parkinson's disease (PD). 8 males subjects diagnosed with PD (69.13 \pm 6.20 years) completed a previously introduced, 8-week, 24-session exercise intervention. A repeated-measures analysis of variance (ANOVA) demonstrated improvements in body composition and muscular strength following the exercise intervention. The data suggests the multifaceted exercise intervention is an effective tool for improving strength and body composition in males diagnosed with PD.
\end{abstract}

\section{Objective}

Approximately 500,000 Americans are affected by Parkinson's disease with nearly a $10 \%$ increase in new documented cases each year [1]. In anticipation of this trend, there is an increased interest in the effects of physiotherapy to improve neurological diseases such as Parkinson's disease (PD). Research has shown that those affected by the progression of $\mathrm{PD}$ are generally weaker, and tend to lose muscle mass more rapidly than healthy populations [2,3]. There is minimal data focusing on multifaceted exercise programs and body composition within the population. Therefore, the purpose of our study is to investigate the effects of a previously introduced active-assisted cycling and resistance training intervention [4], and its effects on body composition and strength in older adult males with PD.

\section{Methods}

Males, 61-74 years of age, diagnosed with PD were recruited from multiple local support groups. All participants successfully completed 24 exercise sessions over an 8-week period. The inclusion criteria for our subjects included a physician's consent as well as a Hoehn and Yahr diagnosis stages 1-3 [5]. Exclusion criteria included symptoms and diagnosis of cardiovascular, metabolic, or respiratory disease. This human subjects study was approved by the Kent State University Institutional Review Board.

Forty eight hours prior (Pre) to the first exercise session, participants completed a baseline assessment of body composition and muscular strength. The assessment included densitometry (weight, body-fat $\%$, fat-free mass, and fat-mass) and the 1 repetition maximum chest press (1-RM) [4]. The assessment was repeated 48 hours subsequent (Post) the final exercise session. The 8 -week exercise intervention consisting of 24 exercise training sessions (Table 1) was administered by a certified personal trainer (ACSM-CPT). The sessions began with a warm-up period of low intensity cycling followed by 5 minutes of flexibility training. Subjects then completed 30 minutes of activeassisted (Motomed Viva 2) aerobic cycling [6]. Following the aerobic training, individuals completed 30 minutes of anaerobic resistance training utilizing weight machines, closed kinetic chain activities, and variable resistance training. Five minutes of balance training was incorporated into the anaerobic training portion of the session. Each session concluded with a 5 minute static flexibility cool-down period. Ratings of perceived exertion (RPE) and heart rates (HR) were monitored during each session. Subjects were asked to maintain a RPE between 11-16 [7]. A two time-point (pre, post) repeated measures analysis of variance (ANOVA) was utilized to examine changes in physical characteristics.

\section{Results}

Eight Caucasian males diagnosed with PD (69.13 \pm 6.20 yrs.; 181.05 $\pm 4.93 \mathrm{~cm}$.) completed 24 multifaceted exercise sessions during an 8 -week training period (Table 2). The ANOVA demonstrated significant ( $p \leq 0.005)$ decreases in body fat $\%$ and fat mass. The analysis also indicated significant increases in muscular strength $(\mathrm{p} \leq 0.001)$. There were non-significant changes in both weight $(\mathrm{p}=0.474)$ and fat-free mass $(p=0.611)$. Aside from multiple physical improvements, subjects also reported an abundance of qualitative improvements including improvements in activities of daily living (ADL's).

\section{Conclusions}

Prior to the investigation, we hypothesized that the aforementioned exercise intervention [4] could improve physical strength and body composition in those diagnosed with PD. Research has previously explored aerobic interventions on physical fitness in both the elderly and the elderly suffering from PD [8]. Data has indicated that aerobic training such as treadmill walking and cycling can improve many symptoms of PD as well as improve physical fitness within the diseased population $[5,6,8]$. Previous research has also indicated physiotherapy as a useful aide to pharmacologic therapy for improving strength and other components of physical fitness in those suffering from PD [9]. Particularly resistance training has revealed enhancements in neural drive and co-activation, both contributing to improved strength and

*Corresponding author: Corey A Peacock, Nova Southeastern University, Exercise and Sports Science,3301 College Avenue, Parker, USA, Tel: 419-618-2968; E-mail: cpeacock@nova.edu

Received: December 21, 2015; Accepted: March 16, 2016; Published: March 23, 2016

Citation: Peacock CA, Sanders GJ, Wilson KA, Fickes-Ryan EJ, Corbett DB, et al. (2016) Effects of an Exercise Intervention on Body Composition in Older Adult Males Diagnosed with Parkinson's disease: A Brief Report. Physiother Rehabil 1: 102. doi: $10.4172 / 2573-0312.1000102$

Copyright: (c) 2016 Peacock CA, et al. This is an open-access article distributed under the terms of the Creative Commons Attribution License, which permits unrestricted use, distribution, and reproduction in any medium, provided the original author and source are credited. 
Citation: Peacock CA, Sanders GJ, Wilson KA, Fickes-Ryan EJ, Corbett DB, et al. (2016) Effects of an Exercise Intervention on Body Composition in Older Adult Males Diagnosed with Parkinson's disease: A Brief Report. Physiother Rehabil 1: 102. doi: 10.4172/2573-0312.1000102

Page 2 of 2

\begin{tabular}{|c|c|c|c|}
\hline Mode & Frequency & Duration & Intensity \\
\hline Aerobic (Active-Assisted Cycling) & 3 days/week & 30 min & $50-85$ RPM Steady-State \\
\hline Anaerobic (multi-joint resistance training ${ }^{\text {) }}$ & 3 days/week & 30 min & $1-2$ sets; $12-15$ reps; $55-67 \%$ of $1-R M$ \\
\hline Flexibility (stretching) & 3 days/week & 10 min total & Static stretching; 20 sec holds \\
\hline Neuromuscular (gait and balance) & 3 days/week & 5 min & 5 sets; 60 sec \\
\hline
\end{tabular}

${ }^{a}$ Resistance exercises include chest press, lat-pull down, shoulder shrug, bicep curl, triceps extension, leg press, leg curl, leg extension, hip bridge, toe/heel raise.

Table 1: Exercise intervention.

\begin{tabular}{|l|c|c|}
\hline Variable & Pre-intervention & Post-intervention \\
\hline Weight (lbs.) & $186.21 \pm 26.97$ & $184.61 \pm 27.53$ \\
\hline Body Fat \% & $25.21 \pm 5.04$ & $22.93 \pm 4.27$ \\
\hline Fat Mass (Ibs.) & $44.71 \pm 9.35$ & $39.72 \pm 8.82$ \\
\hline Fat-Free Mass (lbs.) & $134.89 \pm 15.39$ & $133.10 \pm 8.23$ \\
\hline 1-RM bench press (Ibs.) & $69.75 \pm 35.17$ & $\mathrm{P}=0.005^{*}$ \\
\hline
\end{tabular}

Denotes significance $(p \leq 0.05)(M \pm S D)$.

Table 2: Body composition and strength testing.

movement control [10]. Similar to the previous literature, the exercise intervention provided beneficial physical improvements in the PD sample. As hypothesized, the subjects maintained both weight and fat-free mass while improving body fat \%. Our findings, thus far, suggest that the previously introduced intervention [4] promotes both improvements in body composition and strength specifically in older adult males with PD.

The investigation is unique as it is the first follow-up research utilizing a previously introduced multifaceted physiotherapy intervention [4]. The intervention proved both time efficient (8-weeks) and effective for improving body composition and strength in males diagnosed with PD. Data is currently being analyzed to determine the effectiveness of the intervention as an effective physiotherapy for combating physical decline in males suffering from PD.

\section{Acknowledgements}

Funding was provided by a KSU EHHS Seed grant and a grant from The Foundation for Aging Studies and Exercise Science. There is no conflict of interest. We would like to thank Jacob Barkley, PhD for statistical support.

\section{References}

1. Aarsland D, Andersen K, Larsen J, Lolk A, Nielsen H, et al. (2001) Risk of dementa in Parkinson's disease: a community-based, prospective study. Neurology 56: 730-736.
2. Hirsch M, Toole T, Maitland C, Rider R (2003) The effects of balance training and high-intensity resistance training on persons with idiopathic Parkinson's disease. Arch Phys Med Rehabil 84: 1109-1117.

3. Koller W, Kase S (1986) Muscle strength testing in Parkinson's disease. Eur Neurol 25: 130-133.

4. Peacock C, Sanders J, Wilson K, Fickes-Ryan E, Corbett D, et al. (2014) Introducing a multifaceted exercise intervention particular to older adults diagnosed with Parkinson's disease: a preliminary study. Aging Clin Exp Res 26: 403-409.

5. Burini D, Farabollini B, lacucci S, Rimatori C, Riccardi G, et al. (2006) Radomized controlled cross-over trial of aerobic training versus Qigong in advanced Parkinson's disease. Eura Medicophys 42: 231-238.

6. Ridgel A, Peacock C, Fickes E, Kim CH (2012)Active-assisted cycling improves tremor and bradykinesia in Parkinson's disease. Arch Phys Med Rehabil 93 2049-2054.

7. Robertson R, Goss F, Dube J (2004) Validation of the adult OMNI scale of percieved exertion for cycle ergometer exercise. Med Sci Sports Exerc 36: 102 108

8. Herman T, Giladi N, Gruendlinger L, Hausdorff J (2007) Six weeks of intensive treadmill training improves gait and quality of life in patients with Parkinson's disease: a pilot study. Arch Phys Med Rehabil 88: 1154-1158.

9. Palmer S, Mortimer J, Webster D, Bistevins R, Dickinson G (1986) Exercise therapy for Parkinson's disease. Arch Phys Med Rehabil 67: 741-745.

10. Falvo M, Schilling B, Earhart G (2008) Parkinson's disease and resistive exercise: rationale review and recommendations. Mov Disord 23: 1-11. 